\title{
FORMAÇÃO DOCENTE PARA EDUCAÇÃO A DISTÂNCIA POR VIDEOCONFERÊNCIA E A LINGUAGEM AUDIOVISUAL
}

\section{Preparing Teachers for Distance Education Based on Videoconference and the Audiovisual Language}

\section{Resumo}

Este artigo discute algumas das mudanças que o uso da videoconferência como meio principal para a educação a distância traz para o trabalho do professor. Defende a hipótese de que ocorre uma "midiatização" da sala de aula, pois o meio técnico deixa de ser apenas um recurso adicional e passa a ser o próprio ambiente/interface no qual este tipo de aula pode existir, ampliando as exigências de atuação do professor comunicador como produtor/usuário/mediador. A partir do levantamento das percepções e estratégias dos professores do Mestrado presencial-virtual do Programa de Pós-Graduação em Engenharia de Produção da UFSC, conclui-se que a educação a distância por videoconferência leva à necessidade de formação do "professor midiático", aquele que trabalha dentro do ambiente virtual, dominando a linguagem audiovisual não apenas como ferramenta, mas como essência do seu modo de ensinar.

Palavras-chave: Formação docente; Educação a distância; Videoconferência; Linguagem audiovisual.

1 Doutora, professora do Mestrado em Ciências da Linguagem - UNISUL e do Curso de Comunicação Social - FURB.

E-mail: dulce@furb.br 


\section{Abstract}

The present paper discusses some changes that occur in the teacher's work when videoconference is employed as the main tool in distance education. The hypothesis here supported is that there occurs a "mediatization" of the classroom, since the technical medium, more than a additional tool, becomes the very environment/interface in which this kind of class can happen, thus expanding the demands from the teacher-communicator's performance as a producer/user/mediator. From the assessment of the perceptions and strategies used by the teachers of the conventional-virtual Masters course in the Production Engineering Graduate Program at the Federal University of Santa Catarina (UFSC), one concluded that distance education through videoconference calls for the training of a "mediatic teacher," i.e., that teacher who works within the virtual environment and that handles the audiovisual language not just as a tool, but as the essence of his way of teaching.

Keywords: Teacher training; Distance education; Videoconference; Audiovisual language.

\section{Introdução}

A educação a distância (EAD) no Brasil, apesar da quantidade e qualidade de experiências, não havia se consolidado como uma forma educacional historicamente confiável até a década de 90 . Em meados dos anos 90, no entanto, esse cenário se modificou, pois, ao mesmo tempo em que se ampliava a oferta da televisão educativa/cultural com um conseqüente crescimento na produção de programas educativos para transmissão em rede aberta ou via satélite (tome-se como exemplo a TV SENAC, o canal Futura e o TV Escola), também teve início a entrada progressiva das universidades na educação a distância, utilizando como base as novas mídias geradas pela união entre informática e telecomunicações, como a Internet e a videoconferência. 0 grande avanço aconteceu em 1996, com a aprovação da Lei de Diretrizes e Bases da Educação Nacional (LDB) que instituiu a educação a distância como uma forma de ensino equivalente ao presencial em todos os níveis, apesar de adiar a regulamentação da pós-graduação até o presente momento.

A falta de um apoio legal, no entanto, não foi impedimento para que florescesse a oferta de pós-graduação a distância em algumas universidades brasileiras. Em 1995, o Programa de Pós-Graduação em Engenharia de Produção (PPGEP) criou o Laboratório de Ensino a Distância (LED) que passou a ser o centro de produção das iniciativas de EAD da Universidade Federal de Santa Catarina, a partir de um modelo de mídias integradas: vídeo-aulas, teleconferências, Internet e videoconferência (BARCIA; VIANNEY, 1998). Em 1997, o PPGEP criou o Mestrado na área de Logística para alunos distribuídos em 12 
salas de videoconferência da Petrobrás em todo país. Estes cursos foram enriquecidos com a criação de uma página Web que tinha por objetivo ser 0 ambiente de aprendizagem para apoiar o contato fora do horário de aula entre os professores e os alunos, segundo Moraes (1998) e que passou a ser o modelo utilizado em todos os cursos subseqüentes. Em 1999, começaram os Mestrados na área de Mídia e Conhecimento, para instituições educacionais dos diversos pontos do país. Apesar da falta de regulamentação para a pósgraduação a distância na legislação brasileira, no ano 2000, o chamado "modelo presencial virtual" do Programa de Pós-graduação em Engenharia de Produção da UFSC já se encontrava consolidado (BARCIA; STEIL, 2001).

A videoconferência, utilizada como meio principal para EAD, traz uma série de desafios ao professor, ao permitir que participantes situados em dois ou mais lugares geograficamente diferentes possam realizar uma reunião sincrônica com imagem e som, utilizando câmeras, microfones e periféricos como o CD, o vídeo e o computador como base para apresentações em Power Point, internet, etc. Por essa razão, desde o início do LED, já se esperava que os professores teriam que ser preparados para esse novo modelo, pois a bibliografia mostrava que, para ensinar a distância, de modo geral os docentes precisam exercer uma variedade de talentos e habilidades (ARETIO, 1994). Quando baseada em uma mídia audiovisual interativa, limitações técnicas, recursos didáticos audiovisuais, modos de interação, questões logísticas e afetivas, são aspectos que os professores enfrentam quando entram numa sala de videoconferência e fecham a porta atrás de si (WILLIS, 1994).

Tendo em vista estas considerações, o objetivo da pesquisa descrita neste artigo foi verificar como se daria no caso estudado o ensino pela videoconferência, se ele seria (e como) diferente do presencial, de que maneira os professores iriam vivenciar essa diferença e construir estratégias de uso e de práticas profissionais e, por conseqüência, se haveria necessidade de dar ao professor uma formação especial para trabalhar com a tecnologia e como ela seria estruturada. Para guiar a pesquisa, trabalhou-se com o pressuposto de que a aula pela videoconferência não só se diferencia da presencial como também tem características diversas da educação a distância tradicional, ou seja, é uma aula virtual (KEEGAN, 1995, SIMONSON, 1997). Pode-se acrescentar que, por ser uma inovação tecnológica, os professores exercem sua flexibilidade interpretativa para se adaptar ao novo ambiente estabelecendo estratégias de tradução, de apropriação e uso para o novo ambiente (BIJKER, 1997; LATOUR, 1991). Da mesma maneira, por ser diferente, a aula por videoconferência exige uma formação continuada e adequada para que o docente aprenda a ensinar a partir da reflexão-na-ação, proposto por Schön (1997), utilizando estratégias didáticas adequadas à linguagem audiovisual do ambiente midiatizado. 
Por outro lado, a situação de telepresença da videoconferência problematiza a mediação face a face, o "estar junto" a um tempo e em um lugar que não são os tradicionais de co-presença definidos por Thompson (1998). Com isso, cria-se uma contradição em termos: a co-presença mediada. Neste sentido, ao permitir que a aprendizagem ocorra numa interação de co-presença mediada entre professores e alunos, pode-se dizer que a sala de aula se virtualiza, porque permite que um grupo humano desterritorializado, nãopresente, compartilhe um tempo comum, sincrônico, mas quase independente de um lugar geográfico. Como diria Lévy (1996, p. 21): "a sincronização substitui a unidade de lugar, a interconexão, a unidade de tempo. Mas, novamente, nem por isso o virtual é imaginário. Ele produz efeitos". Um dos efeitos pode ser o de que, embora não se saiba "onde", a conversação tem lugar.

A videoconferência virtualiza a sala de aula também porque problematiza o papel do professor. Ao incluir a obrigatoriedade do conhecimento tecnológico como condição de existência da aula, amplia as exigências de atuação do professor, que precisa dominar todos os recursos e operar câmeras e microfones para que ocorra a comunicação com os alunos e, por conseqüência, a aprendizagem. Se na escola tradicional ele pode escolher "enriquecer" sua aula com a incorporação da nova lógica que a mídia traz, na educação a distância por videoconferência ele está "imerso" no meio televisivo. Este lugar é virtual, pois permite a interação ao mesmo tempo presencial - onde de fato estão os participantes, em suas salas audiovisuais, tácteis e olfativas - e é midiático - pois a comunicação é audiovisual e acontece no ciberespaço, ou seja, na interface, como diria Lévy (1999).

Dessa maneira, para se tornar um professor comunicador, proposto por Fusari (1994), o docente precisa desenvolver competências de uma nova linguagem midiática para adequar-se às características do meio televisão e, ao mesmo tempo, tomar-se um produtor/usuário/mediador. Se a aula pela videoconferência acontece por uma interação mediada, por meio de instrumentos técnicos que a compõem e que vão configurar, são justamente suas limitações e possibilidades que definirão o modo como a comunicação irá ocorrer. Dessa maneira, propôs-se como hipótese que o que ocorre na educação a distância por videoconferência é uma "midiatização" da sala de aula, pois o meio técnico deixa de ser apenas um recurso adicional e passa a ser o próprio ambiente/ interface no qual este tipo de aula pode existir (CRUZ, 2001).

Nessa midiatização da sala de aula, as tecnologias passam a constituir e definir o ambiente de ensino, o entorno e o meio a partir do qual a situação de aprendizagem ocorre. Um dos efeitos da midiatização é que a sala de aula tem que passar por uma reformulação estrutural para que sejam incluídos os instrumentos da mídia (câmera, microfones, aparelhos de TV, computadores) e seus processos comunicativos especiais (linguagem audiovisual, interativi- 
dade, questões relativas à virtualização da comunicação e da distância física). A midiatização da sala de aula ocorre, então, como um processo de transformação do espaço educativo no qual professores e alunos criam novas rotinas e relações a partir de parâmetros nunca vistos na história da educação (CRUZ, 2001).

\section{Materiais e Métodos}

Os resultados descritos neste artigo fazem parte de uma pesquisa que investigou o trabalho do professor na EaD por videoconferência e se era preciso formá-lo para o ambiente virtual a partir de um estudo de caso dos cursos a distância por videoconferência na Pós-Graduação em Engenharia de Produção da Universidade Federal de Santa Catarina, entre 1996 -2000, a partir de observação participante. A coleta de dados foi realizada a partir do acompanhamento das aulas e de entrevista com os professores envolvidos e do levantamento de informações geradas pelas oficinas de formação docente realizadas no período da pesquisa.

A amostra foi determinada a partir do envolvimento do professor com o ensino a distância, o que significa que se incluíram, a priori, todos os que ministrassem aulas por videoconferência, escolhidos para participar da pesquisa por métodos não probabilísticos. As variáveis investigadas foram agrupadas em roteiros para entrevistas semi-estruturadas, elaboradas sob a forma de perguntas abertas. No total, foram pesquisados 28 docentes que tinham ministrado até o início de 2000, 86 disciplinas, para um universo total de 51 professores e 145 disciplinas. Além disso, foram analisados os questionários de avaliação respondidos pelos 88 docentes que participaram das doze oficinas realizadas pela pesquisadora entre 1999 e 2001.

\section{Resultados}

Já a partir do primeiro ano de instalação dos equipamentos, a equipe do Laboratório de Ensino a Distância realizou diversas experiências para desenvolver um formato tanto pedagógico quanto técnico que pudesse ser utilizado como uma resposta às necessidades que foram nascendo a cada novo curso. No momento em que o estúdio individual para o professor passou a ser a "melhor" solução, todos os esforços da equipe de implementação se voltaram para a resolução ergonômica do posto de trabalho.

Como os profissionais envolvidos possuíam uma experiência com produção de televisão, o "estúdio" foi gradativamente adquirindo característi- 
cas de um cenário: foram testadas várias maneiras de se iluminar o posto do professor, a parede foi revestida para se conseguir maior isolamento acústico, a cor escolhida do revestimento foi a azul para gerar uma sensação de fundo infinito, comum nos estúdios de TV; foi construído um cenário ao fundo, com os logotipos do Laboratório, do Programa e da Universidade colocados estrategicamente para que fossem enquadrados pela câmera num ângulo mais aberto; num ângulo de câmera mais fechado, a equipe preocupou-se em deixar um fundo liso, sem que houvesse um "ruído" de outros elementos que poderiam atrapalhar a imagem do professor; a iluminação também foi planejada para dar um destaque do fundo, gerando uma sensação de profundidade para a imagem do professor ao mesmo tempo em que gerava uma imagem limpa, clara e sem sombras. Todos esses detalhes vêm sendo mantidos até hoje com pequenas alterações e serviram de exemplo para outros estúdios de videoconferência em universidades e empresas no Brasil.

É importante frisar que a definição por um estúdio individual para o professor representou não apenas a opção por um cenário, mas a determinação das condições possíveis para um modo específico de usar a videoconferência para o ensino. Ou seja, ao se definir o formato da sala e o posto de trabalho do professor a partir da idéia de um espaço comunicacional audiovisual interativo, que tivesse um "efeito" na audiência no sentido proposto por Ferrés (1996), chegou-se também a uma linguagem, que pode ter influenciado o modo como os professores pensaram suas maneiras de ensinar no ambiente tecnológico. Vale afirmar que nas experiências levantadas na bibliografia e universidades visitadas por esta pesquisadora, não foi encontrada a mesma preocupação audiovisual para o cenário nem mesmo para o que o espaço representaria para o professor como um local de trabalho com limitações e características próprias.

O resultado das entrevistas e do acompanhamento das aulas, por outro lado, mostrou que a educação a distância por videoconferência representou uma série de mudanças na rotina dos professores. O acréscimo da mediação tecnológica e a perda de contato físico com os alunos levaram os professores a tentar suprir as carências sentidas por compensações adaptadas para o ambiente audiovisual. Percebe-se pelos depoimentos que os professores tentaram adaptar ao máximo seu modo de trabalhar às necessidades do ambiente da videoconferência, buscando alterar minimamente sua rotina profissional e desenvolvendo estratégias conhecidas, mas utilizadas de um modo novo. Tanto que as técnicas de ensino e as formas de avaliação mantiveram suas características básicas e foram modificadas apenas quando se mostraram impossíveis de ser realizadas de outra maneira.

A ausência de uso de determinadas funções da videoconferência demonstrou que os professores escolhiam o que queriam dentro do ambiente 
virtual. As configurações possíveis e as constantes modificações nas condições de trabalho mostraram que os professores não sofreram o impacto da técnica, mas sim trabalharam melhorias ou abandonaram hipóteses, num processo dinâmico de avanços e retiradas. Pode-se ver que havia professores interessados em criar e investigar o que o ambiente possibilitava de novas maneiras de ensinar. Mas não foram poucos os que se contentaram com o mínimo confortável, dando-se um tempo para aprender devagar as novas possibilidades antes de se jogar de cabeça no inusitado.

No trabalho de negociação de sentido, os atores traduziram constantemente seus significados, gerando e modificando os papéis e as ações exigidas na interação com a tecnologia. Isso pode ser percebido no modo de construir a aula. Os limites técnicos foram muitas vezes decisivos para a continuidade ou não das ações. Em muitos depoimentos, a sensação de formalização e de rigidez sentidas na aula pela videoconferência se refletiu num aumento do tempo de exposição, ou mesmo, na ênfase deste tipo de estratégia, para compensar as dificuldades de comunicação. Por outro lado, o efeito inverso foi o de intensificar a produção de aulas estruturadas em transparências, que davam ao professor a satisfação de estar utilizando a potencialidade audiovisual do ambiente, quando, na verdade, estava diminuindo as chances de diálogo e interação espontânea dos alunos e de dinâmicas mais participativas e coletivas.

Um dos maiores problemas de adaptação vindo das limitações técnicas foi o da dificuldade de perceber as deixas ou indicadores verbais e não verbais. Essas deixas, como signos, sinais e mensagens, servem para o professor dimensionar as atitudes afetivas e cognitivas dos alunos e são chaves para medir a efetividade do ensino (MARLAND, 1997). Ao ter menos oportunidades de levantar essas deixas por causa da baixa qualidade de visualização, de audição e a falta do costume de trabalhar prestando atenção na tela da televisão, os professores tinham um inventário bem reduzido de conhecimento sobre os estudantes individualmente, o que tornava sua interpretação mais problemática. Pelos depoimentos, percebeu-se que os professores, cada um a seu modo, tentou buscar meios de aumentar a quantidade e a qualidade dos contatos com os alunos a distância, visando a aumentar as deixas recebidas no ambiente virtual.

A questão do encontro presencial foi um dado que mostrou implicações importantes no entendimento dessas relações virtuais. Nas primeiras etapas dos cursos a distância, os professores que não se encontravam com os alunos no início do curso relataram que não sentiram falta da presença física, contentando-se em estar virtualmente conectados. Quando esses encontros passaram a ser freqüentes, o grupo dos professores que participou de aulas presenciais iniciais foi unânime em apontar a importância de se encontrar face 
a face com os alunos, para ampliar o conhecimento sobre eles. Esses dados nos levam a ver uma relação entre a capacidade que os meios frios e quentes, como diria McLuhan (1967), tem de suprir ou não o que é necessário para um envolvimento professor/alunos. Sem a possibilidade de ter o contato pessoal, mas supostamente recebendo todas as deixas pelo equipamento audiovisual (o meio quente da TV), os professores tinham sensação de que não faltava nada para completar a "representação mental" dos alunos e ficavam satisfeitos. Quando confrontados com a riqueza do encontro face a face e o início de um relacionamento "mais humano", os professores podiam comparar as diferenças entre os dois tipos de mediação e percebiam mais claramente as carências e limitações da interface técnica.

Muitas das dificuldades narradas pelos professores têm a ver com a ausência de uma alfabetização dos meios audiovisuais e o desejo de preparar os materiais didáticos de um modo mais adequado para o ambiente virtual. Os depoimentos demonstraram que os professores gostariam de fazer uma aula mais "animada", mais rica em recursos audiovisuais. Alguns chegaram a utilizar alunos bolsistas para incrementar suas transparências e torná-las menos textuais, mais bonitas e coloridas. Talvez pela percepção de que estavam envolvidos num ensino que precisava de uma linguagem audiovisual, os professores faziam referência ao uso dos enquadramentos de câmera como se fossem ao mesmo tempo recursos didáticos e afetivos ou até se desculpavam por ainda não conseguir usar direito o que haviam visto nas oficinas de formação. Essas referências remetem à afirmação de Perrenoud (2000) sobre a competência para ensinar com tecnologias. Segundo o autor, não basta apenas conhecer e aprender a usar os instrumentos, é preciso desenvolver uma capacidade de dominar a lógica que eles trazem, que demandam e proporcionam uma mudança de paradigma. A verdadeira incógnita, diz ele,

é saber se os professores irão apossar-se das tecnologias como um auxílio ao ensino, para dar aulas cada vez mais bem ilustradas por apresentações multimídia, ou para mudar de paradigma e concentrar-se na criação, na gestão e na regulação de situações de aprendizagem (op. cit., p. 139, grifo do autor).

Nesse caso, as respostas dos professores só confirmam a pouca familiaridade com recursos audiovisuais que vêm sendo há muito tempo demonstrado nas pesquisas sobre o ensino tradicional. A diferença neste caso foi que a vantagem de ter à disposição os recursos multimídia não representou um aumento na sua utilização pelos professores. Pode-se inferir ainda que o problema não é o acesso, mas o desconhecimento das potencialidades e a dificuldade em conciliar os diferentes afazeres profissionais, já que a falta de tempo foi muitas vezes lembrada como o grande empecilho para que os próprios professores produzissem seus materiais de um jeito diferente. 
Mas foi justamente o passar do tempo que ajudou os professores a aprender a interagir com a tecnologia. Pelos depoimentos e pela observação das aulas, pudemos perceber que conforme iam trabalhando e se familiarizando com o ambiente virtual, os professores foram modificando suas expectativas e adotando comportamentos diferentes. Neste sentido, pode-se dizer que houve uma semelhança com as etapas de apropriação (exposição, adoção, adaptação, apropriação e invenção) descritas por Sandholtz; Ringstaff; Dwyer (1997). Isso porque, nos depoimentos da fase inicial, a de exposição, os professores demonstraram uma maior preocupação com a tecnologia e em sua habilidade de manter o controle sobre a sala e os estudantes, gastando uma considerável parcela de tempo reagindo aos problemas em vez de antecipálos e evitá-los. Uma grande parte dos professores conseguiu ultrapassar essa fase, passando para a seguinte, a de adoção, começando não somente a antecipar os problemas, mas a desenvolver estratégias para resolvê-las. Alguns professores demonstraram ter chegado ao momento seguinte, o de adaptação, pois conseguiram focar nos efeitos de sua prática de ensino sobre os alunos, utilizando a tecnologia de modo vantajoso para administrar a sala de aula. No entanto, poucos professores conseguiram entrar no estágio de apropriação e invenção, no qual as preocupações de administração diminuem conforme suas abordagens instrucionais e estratégias de gerenciamento vão se tornando interligadas.

Este modo com que os professores utilizaram os recursos da videoconferência pode ser também identificado com os critérios (vantagem relativa, compatibilidade, complexidade, grau de experimentação e de comunicação) que, segundo Rogers (1983), influenciam a velocidade com que uma inovação vai ser adotada ou não. A vantagem relativa do curso por videoconferência, quando comparada com o presencial, foi percebida como uma série de ganhos que, de longe, compensou as perdas, mostrando até ser melhor em muitos aspectos que a educação existente. Comparada com a internet, a videoconferência também foi vista como tendo uma vantagem relativa, tanto pela facilidade de uso, quanto pela sua importância no processo, já que era vista como "a aula" em si.

Em termos de compatibilidade, a videoconferência demonstrou ser consistente com valores prevalecentes, práticas e experiências das aulas presenciais, possibilitando a adaptação de materiais e conteúdos e técnicas de ensino já conhecidas do professor. Além disso, o grau de complexidade dos equipamentos, mesmo que assustador no início, não foi visto como muito alto, nem de difícil entendimento ou uso, permitindo que os professores pudessem testar e experimentar, não apenas antes, mas durante as aulas. Pesou para essa percepção, a comunicação que houve entre os professores já experientes e os iniciantes, que eram acalmados com a informação de que não era 
tão difícil assim "pegar o jeito". Além de tudo, a visibilidade dos cursos pela videoconferência, tanto entre os pares, como em nível regional e nacional, fez com que os professores se sentissem valorizados ao engajar-se nas aulas a distância, consideradas como um desafio motivador.

\section{Considerações finais}

Este artigo defendeu que a aula pela videoconferência é um novo tipo de educação a distância, que exige que se repense a atuação e a preparação do professor. No ambiente da videoconferência, chamado aqui de virtual ou midiatizado, os professores colocaram em xeque seu modo de ensinar para se adaptar às limitações e condições técnicas possíveis ali. Como um ambiente estranho, a aula pela videoconferência levou os professores a questionar o que já estava fechado no ensino presencial, ao comprometer, entre outros, os parâmetros conhecidos do espaço físico da aula, da passagem do tempo, do tipo de relação afetiva que se estabelecia e das condições necessárias para que houvesse um diálogo entre professores e alunos. Neste sentido, uma das conclusões mais surpreendentes dos depoimentos dos professores foi a constatação de que, no ambiente tecnológico, as relações se humanizaram mais, ao invés de perderem seu caráter emocional.

Além disso, a importância de se perceber até onde foi o desenvolvimento dos professores e por que ele aconteceu desse modo, é crucial para se pensar a qualidade dos cursos a distância. Em primeiro lugar, porque dois fatores demonstraram ser fundamentais para a aprendizagem do professor: 0 tempo e a preparação. Os professores que tiveram a chance de dar muitas disciplinas, mesmo que não tivessem tido um treinamento, acabaram aprendendo por tentativa e erro, testando suas teorias e percebendo o que funcionava ou não, melhorando suas aulas a cada dia. Conseguiram passar pelas etapas iniciais em que a técnica era o foco e chegar ao processo de ensino/ aprendizagem midiatizado. Aqueles professores que ministraram poucas disciplinas não puderam avançar na sua performance e, provavelmente, fizeram seus cursos presos às limitações técnicas do ambiente, não chegando a usufruir as vantagens da educação virtual. O crucial da questão é que, se os dois grupos de professores tivessem passado por uma formação continuada, poderiam ter aproveitado mais seu potencial e conduzido melhor suas aulas, podendo passar mais rápido ou mais facilmente pelas etapas de apropriação.

Com isso, queremos dizer que a aula por videoconferência é realmente uma aula diferente da aula presencial e, por essa razão, os professores não podem simplesmente ser jogados no ambiente virtual sem que estejam conscientes do que é possível ou não fazer ali. Negar ao corpo docente essa 
formação pode ter como conseqüência a diminuição da qualidade possível dos cursos. Esse fato pode ser agravado ainda mais se há uma rotatividade dos professores, o que significa um maior número de iniciantes subutilizando não só seu próprio potencial, mas o da educação a distância por videoconferência de modo geral. Negar que os professores também precisam ser formados enquanto estão ensinando, e não apenas no início, é, da mesma maneira, perder a possibilidade de apressar a qualificação docente, não ajudando os professores a se livrar das amarras técnicas para exercer sua criatividade plenamente.

O primeiro passo para inverter essa situação é o de entender a aula pela videoconferência como virtual. A denominação "presencial-virtual" - utilizada como forma de viabilizar os cursos da UFSC, num cenário de ausência de regulamentação da pós-graduação a distância no Brasil - pode, de certa maneira, mascarar os requisitos essenciais da aula midiatizada. $\mathrm{O}$ conceito presencial-virtual pode ser entendido, no caso estudado, como um modelo de curso que inclui momentos virtuais com encontros presenciais, mas não pode ser confundido com a caracterização da aula que ocorre pela videoconferência, que como se viu, é "apenas" virtual. Entender que a aula pela videoconferência é virtual reivindica novos parâmetros de categorização dessa modalidade de educação a distância.

Uma demonstração do que ocorre de novidade no trabalho do docente é a de que, na aula pela videoconferência nos cursos da UFSC, não acontece a divisão de tarefas característica da EAD, a tal ponto que fica difícil identificar "quem" está ensinando, como afirma Belloni (1999). Pelo contrário, pode-se argumentar que a função docente na videoconferência "é" do professor e de mais ninguém. Apesar da aula necessitar de técnicos, monitores e administradores para que aconteça, "dentro" do ambiente virtual da videoconferência o professor é o único responsável pelo que ocorre ali. São suas as escolhas que definem o conteúdo, as dinâmicas, a interação, o modo construtivista ou bancário de ensinar. Mais ainda, depois que a porta do estúdio se fecha sobre si, o professor passa a trabalhar como se estivesse em sua sala de aula presencial, não dividindo sua função docente com nenhum outro profissional, acumulando funções, operando os equipamentos, dirigindo o som e a imagem. Nesse sentido, ele não usa a técnica para incrementar sua aula, ele está dentro da técnica, as ferramentas são a extensão do seu ser, o meio é sua mensagem. Este, no nosso entender, é o "professor midiático", que poderia ser definido como o profissional que dirige individualmente o processo de aprendizagem de alunos a distância, responsabilizando-se totalmente pela produção ou escolha dos conteúdos, pela qualidade do material didático, pela decisão, planejamento e cumprimento dos objetivos pedagógicos e, finalmente, pela operação dos equipamentos técnicos necessários para o desenvolvimento da aula. 
É por essa razão que afirmamos que é preciso formar o professor midiático, aquele que não apenas media o processo do conhecimento, mas trabalha dentro da interface, dominando o audiovisual não apenas como uma ferramenta, mas como a essência do seu modo de trabalhar. O conceito de professor midiático mostrou-se adequado para descrever as novas funções docentes no ambiente virtual, imerso na comunicação a distância, potencializado pela tecnologia e ainda em processo de aprendizagem sobre suas tarefas e comportamentos.

Finalmente, como um argumento favorável ao investimento para formação do professor midiático, pode-se afirmar que seu trabalho não se esgotará com a evolução técnica. Pelo contrário, é justamente a formação para 0 ambiente virtual que vai permitir que seu trabalho possa se adaptar para 0 salto tecnológico que se aproxima, com a mudança de plataforma da videoconferência de sala para o desktop, possibilitada, entre outros fatores, pela expansão das bandas largas de transmissão. Por essa razão, os aspectos levantados neste estudo podem ser perfeitamente estendidos para quando o ambiente virtual for, por exemplo, o computador doméstico, capacitado com câmera e microfone para que o professor se comunique diretamente com seus alunos, que estarão não mais necessariamente em grupos, mas continuarão a ser encontrados no ciberespaço, desterritorializados, virtuais. Concordar com essa afirmação implica em aceitar que a necessidade de investir na formação docente para a linguagem audiovisual não é apenas para o presente, mas para o futuro.

\section{Referências}

ARETIO, Lorenzo García. Educación a distância hoy. Madrid: Universidad Nacional de Educacion a Distância, 1994.

BARCIA, Ricardo Miranda, STEIL, Andrea. La enseñanza a distância, la ingeniería y la producción. In: ENCUENTRO INTERNACIONAL SOBRE EDUCACIÓN SUPERIOR VIRTUAL E INTERACTIVA. Anais... Mexico: Monterrey/UNESCO, 2001.

BARCIA, Ricardo Miranda, VIANNEY, João. Pós-graduação a distância: a construção de um modelo brasileiro. Estudos: Revista da Associação Brasileira de Mantenedoras de Ensino Superior, Brasília, v. 16, n. 23, p. 51-70, 1998.

BELLONI, Maria Luiza. Educação a distância. Campinas: Autores Associados, 1999. 
BENAKOUCHE, Tamara. Educação a distância (EaD): uma solução ou um problema? In: ENCONTRO ANUAL DA ANPOCS, 24. Petrópolis, 2000. Anais... Petrópolis:[s. n.], 2000.

BIJKER, Wiebe E. Of bicycles, Bakelites and Bulbs: towards a theory of sociotechnical change. Cambridge: The MIT, 1997.

CRUZ, Dulce Márcia, BARCIA, Ricardo Miranda. Educação a distância por videoconferência. Tecnologia Educacional, v. 28/29, n. 150/151, p. 3-10, jul/ dez., 2000.

CRUZ, Dulce Márcia. O professor midiático: a formação docente para a educação a distância no ambiente virtual da videoconferência. Florianópolis, 2001. 1977. Tese (Doutorado) - Universidade Federal de Santa Catarina. Disponível em: http://teses.eps.ufsc.br/defesa/pdf/1327.pdf Acessado em: 03 nov 2003.

FERRÉS, Joan. Vídeo e educação. 2. ed. Porto Alegre: Artes Médicas. 1996.

FUSARI, Maria Felisminda de Rezende e. Televisão e vídeo na formação de professores de crianças. INTERCOM - Revista Brasileira de Comunicação, v. 17, n. 1, p. 42-57, jan./jun. 1994.

KEEGAN, Desmond. Distance education technology for the new millenium compressed video technology.ZIFFPapiere 101, ERIC Document Reproduction, 43 p, 1995.

LATOUR, Bruno. Technology is society made durable. In: LAW, J. (ed.) A sociology of monsters: essays on power, technology and domination. London: Routledge, 1991. p. 103-131.

LÉVY, Pierre. Cibercultura. São Paulo, SP: Ed. 34, 1999.

. O que é vir tual ? São Paulo, SP: Ed. 34, 1996.

MARLAND, Perc. Towards more effective open \& distance teaching. London: Kogan, 1997.

MCLUHAN, Marshall. The medium is the Massage: an inventory of effects. San Francisco: HardWired, 1967.

MORAES, Marialice de etal. Media Convergence in the Virtual University: a Brazilian Experience. In NAU/WEB.98, Flagstaff: EUA, 1998. Disponível em http:// star.ucc.nau.edu/ nauweb98/proposals/moraes.html. Acessado em: 03 nov. 2003. PERRENOUD, Philippe. Dez novas competências para ensinar. Porto Alegre: Artes Médicas Sul, 2000. 
ROGERS, Everett. M. Diffusion of inovations. New York: The Free, 1983.

SANDHOLTZ, Judith Haymore, RINGSTAFF, Cathy, DWYER, David C. Ensinando com tecnologia: criando salas de aula centradas nos alunos. Porto Alegre: Artes Médicas, 1997.

SCHÖN, Donald. A Formar professores como profissionais reflexivos. In: NÓVOA, A. (Coord.). Os professores e sua formação. 3. ed. Lisboa: Dom Quixote, 1997.

SIMONSON, Michael. (Coord.). Distance Education: review of the literature. 2. ed. Washington: AECT/RISE, 1997.

THOMPSON, John B. A Mídia e a Modernidade: uma teoria social da mídia. Petrópolis: Vozes, 1998.

WILUS, Barry. (Ed.). Distance Education Strategies \& Tools. Englewood Cliffs, NJ: Educational Technology, 1994. 